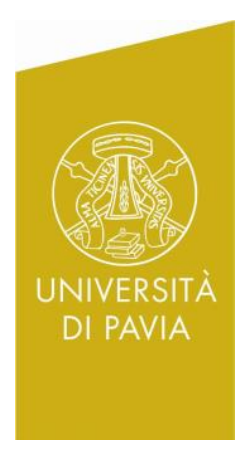

Department of Economics and Management DEM Working Paper Series

\title{
A novel approach for testing the parity relationship between CDS and credit spread
}

\author{
Carolina Castagnetti \\ (Università di Pavia)
}

\# $161(06-18)$

Via San Felice, 5

I-27100 Pavia

economiaweb.unipv.it

June 2018 


\title{
A novel approach for testing the parity relationship between CDS and credit spread
}

\author{
Carolina Castagnetti*1 \\ ${ }^{1}$ Department of Economics and Management, University of Pavia, Italy
}

June 6, 2018

\begin{abstract}
We test the CDS-credit spread arbitrage by taking into account the presence of an unobserved common factor structure driving the movement in the prices. We examine 193 European CDS-Bond basis from January 2007 to December 2009. We estimate one and two common factors for the corporate bond spreads and the CDS premia, respectively. We address the issue of cross-member cointegration by adopting a novel approach. While standard cointegration techniques support the parity relation, the novel approach discards this hypothesis.
\end{abstract}

Keywords: factor error structure; cross-section dependence; credit default swaps; limit of arbitrage.

JEL - Classification: C23,G12.

\section{Introduction}

In the past several years, credit derivatives have begun trading actively in financial markets and they are rapidly becoming one of the most successful financial innovations of the past decade. Among various credit derivative instruments the credit default swap (CDS) is the most widely

${ }^{*}$ Correspondence to: Dipartimento di Scienze Economiche e Aziendali, Via San Felice 5, 27100 Pavia (Italy). E-mail: carolina.castagnetti@unipv.it. 
traded capturing nearly half of the market (Zhu, 2006). In a CDS, the party buying protection pays the seller a fixed premium each period until either default occurs or the swap contract matures. In return, if the underlying firm defaults on its debt, the protection seller is obligated to buy back from the buyer the defaulted bond at its par value.

Reduced-form models provide a framework to connect corporate bond (CB) spreads with CDS premia. Using the risk neutral default probability and no-arbitrage conditions, it is straightforward to establish the parity relationship between the two spreads. The parity relationship between $\mathrm{CB}$ and CDS has been supported with evidence of a cointegration relationship between the two series by Blanco et al. (2005), Zhu (2006), Norden and Weber (2009) and Forte and Pena (2009), among others. The intuition is that, if credit risk is priced equally between the derivatives market and the corporate bonds market, we expect a long run relationship between the two series; i.e. they should be linearly cointegrated.

Longstaff et al. (2005) use weekly data and find that price differentials between CB and CDS prices can be largely explained by measures of individual corporate bond illiquidity. Blanco et al. (2005) show that the parity relationship between the two credit spreads holds on average over time for most entities, but substantial deviation can arise in the short run either because of imperfections in contract specifications or due to a clear lead for CDS premia over CB spreads. Zhu (2006), consistent with previous studies, confirms that the theoretical parity relationship between the two credit spreads holds as an equilibrium condition. In other words, although market developments can cause different changes in CB spreads and CDS premia, there exists a long-run relation tying the two prices together, i.e., that they should be equal to each other in equilibrium.

This paper extends the existing studies on testing the validity of a theoretical arbitrage relation equating CDS and CB by relying on a novel approach for testing cointegration when the series are characterized by the presence of a common factor structure. The evidence of cross section dependence in the the corporate bonds market has been widely documented in the empirical literature, see Campbell and Taksler (2003), Castagnetti and Rossi (2013) and Castagnetti et al. (2017). We test the validity of a theoretical arbitrage relation equating CDS prices to credit spreads for a sample of 193 European investment-grade firms for which high- 
quality time-series data are available. While standard cointegration techniques support the parity relation, suggesting that the bond and CDS markets price credit risk risk equally, the novel approach discards this hypothesis.

\section{Data Description}

We extract bond data from the IBOXX Euro Bond Index. This index is issued by seven major investment banks ${ }^{1}$ that commit to buy and sell every single asset belonging to the index. The rules of inclusion of the bonds to the Index guarantee that only tradable and liquid bonds are included. We consider bonds with standard cashflows - fixed rate coupon and principal at maturity - only. We exclude all unrated bonds, step-up notes, floating rate debt and convertible bonds. We also exclude bonds with call options, put options or sinking fund provisions. Then we select and match each bond whose firm's CDS is traded in the derivative market and transactions are recorded in the Markit database. The prices of CDS are quoted in basis point per annum for a notional value of 10 million euro and are based on the standard ISDA contract for physical settlement. We consider CDS with a maturity of five years, because the 5-year CDS is by far the most liquid in the credit derivative market, and this is also the one mostly used in the literature. We end up with 193 bonds for 35 monthly observations. The sample extends from January 2007 to December 2009.

\section{Empirical Analysis}

The first step of the analysis is the investigation of the stationarity properties of the data. The most commonly used panel unit roots tests are those proposed by Levin et al. (2002) and Im et al. (2003). ${ }^{2}$ However, Larsson and Lyhagen (2000) investigate how the distribution of different tests, including the two mentioned above, is affected by the presence of a common factor and find that they perform poorly especially when the number of cross section increases. Therefore, we rely on the PANIC unit root test proposed by Bai and Ng (2004) that takes into account the

\footnotetext{
${ }^{1}$ ABN AMRO, Barclays Capital, BNP Paribas, Deutsche Bank, Dresdner Kleinwort Wasserstein, Morgan Stanley and UBS Investment Bank.

${ }^{2}$ It is well known in the literature that panel based unit root tests have higher power than unit root tests based on individual time series and panel data techniques are also preferable because of their high degree of flexibility.
} 
error cross-section dependence in the data given to the presence of unobserved common factors.

Bai and $\mathrm{Ng}(2004)$ assume the following factor structure for the observed panel data $Y_{i t}$ :

$$
Y_{i t}=\lambda_{i}^{\prime} F_{t}+e_{i t}
$$

where $F_{t}$ is a $(k \times 1)$ vector of common factors, $\lambda_{i}$ is a vector of factor loadings and $e_{i t}$ is an idiosyncratic component. Hence, the series $Y_{i t}$ is given by the sum of a common component $C_{i t}=\lambda_{i}^{\prime} F_{t}$ and an idiosyncratic error, $e_{i t}$. The series may be non-stationary if either $F_{t}$ or $e_{i t}$ (or both) are non-stationary. Bai and Ng (2004) propose to test both components separately. ${ }^{3}$

Table 1: Bai $\operatorname{Ng}(2004)$ unit root tests

\begin{tabular}{lccccc}
\hline variable & $\begin{array}{c}\text { number } \\
\text { of factors }\end{array}$ & $Z_{e}^{c}$ & $A D F^{c}$ & $M Q_{f}^{c}$ & $\begin{array}{c}\text { number } \\
\text { of factors }\end{array}$ \\
\hline$C D S$ & 2 & 34.65 & & -21.73 & 2 \\
$C B$ & 1 & 37.879 & -1.52 & & \\
\hline
\end{tabular}

Note: the suffices ${ }^{c}$ for the statistics $Z, A D F$ and $M Q_{f}$ indicate the intercept only case. ${ }^{*}$ The IPC3 criterion of Bai and $N g$ (2002) was used to estimate the number of unobserved common factors. ${ }^{* *}$ Number of factors estimated by the $M Q_{f}$ statistics.

The $Z_{e}$ tests of Bai and $\mathrm{Ng}$ (2004) reject the null of unit root for the estimated idiosyncratic component of both the CDS and the CB spread as presented in table 1. Hence, the Bai and Ng (2004) tests tell us that the non-stationarity of the data considered is not due to the idiosyncratic errors but is entirely due to unobserved common components, i.e. the non-stationarity in the observed data is due to a pervasive source. Estimating a single common factor ${ }^{4}$ for the $\mathrm{CB}$ spread the $A D F$ tests does not reject the unit root hypothesis. ${ }^{5}$ Estimating 2 common factors for the CDS premium, both $M Q_{f}^{c}$ and $M Q_{f}^{\tau}$ cannot reject the null hypothesis that there are 2 independent stochastic trends. ${ }^{6}$

For the cointegration analysis we follow Blanco et al. (2005), Forte and Pena (2009) and

\footnotetext{
${ }^{3}$ If the series may be represented by (1), testing for the presence of unit root in $Y_{i t}$ could provide misleading results. If, for instance, one component is $I(0)$ and one is $I(1)$ unit root tests on $Y_{i t}$ are oversized while stationarity tests have low power. See Ng and Perron (2001).

${ }^{4}$ We use the IPC3 criterion of Bai and Ng (2002) to estimate the number of unobserved common factors and we allow for at most 4 factors. However, the results shown are robust to using other selecting criterions and selecting a different maximum numbers common factors allowed.

${ }^{5}$ The critical value for $A D F^{\tau}$ is -3.41 .

${ }^{6}$ The critical values for the two statistics are -23.535 and -31.356 , respectively. See Bai and Ng (2004), Table I.
} 
Zhu (2006) for the specification of the cointegration relationship. Since theory predicts that the two prices should be equal, we only need to test the stationarity of the basis spread, which is defined as the difference between the CDS spread and the CB spread. If each of the two prices follows an I(1) process, and the basis spread is stationary, the equivalence relationship predicted by the theory is not rejected. In other words, there is no arbitrage opportunity between the two markets in the long run. For 109 out of 193 bonds, the ADF test reject the null hypothesis of presence of unit root in the first stage residuals. ${ }^{7}$ Hence, about $56 \%$ of our bonds supports the hypothesis of a cointegration relationship among CDS and CB spreads. Because we are considering matching CDS with CS with different maturity if we closely look at the relation considering only bonds with maturity equal to 5 and the corresponding CDS contract we find that for 21 out of 26 issues with a maturity closed to 5 years we reject the null of unit root in the first stage residuals. At this stage of the analysis, the evidence supports the equilibrium in the credit market.

However, the univariate Engle-Granger test assumes no cross-unit cointegration, ${ }^{8}$ an assumption that is usually not warranted, especially when considering macroeconomic or financial data with strong intra-economic linkages. Banerjee et al. (2004) shows that when the hypothesis of absence of cointegration across units is violated, both univariate and multivariate tests display severe size distortions.

On the contrary, the framework developed by Bai and Ng (2004), analyzing the common factors and idiosyncratic components separately, allows for cross-unit cointegration. ${ }^{9}$ Following Gengenbach et al. (2006), we focus on testing for no-cointegration when the cross-sectional dependence in the panel is modelled by the PANIC approach of Bai and Ng (2004). Gengenbach et al. (2006) address the issue of no-cointegration at three possible different levels: 1) testing for idiosyncratic component no-cointegration when the observed non-stationarity in the series originates from idiosyncratic stochastic trends only, 2) testing for common factors no-cointegration when the non-stationarity is due to cross-sectional common trends only, 3) testing for panel no

\footnotetext{
${ }^{7}$ The number of lags in ADF statistics of each bond is selected according to the Schwarz criterion.

${ }^{8}$ Consider, the non-stationary variable $y_{i t}$. The panel units are cross-cointegrated if there exists a linear combination of $y_{1 t}, \ldots, y_{N t}$ that is stationary. For a formal definition of cross-unit cointegration, see Wagner and Hlouskova (2010).

${ }^{9}$ See also Breitung and Pesaran (2008).
} 
cointegration when there are both cross-sectional common and idiosyncratic stochastic trends.

The results of PANIC analysis reported in Table 1, have entirely attributed the non-stationarity in the panel to a reduced numbers of common stochastic trends, i.e. we address the issue of cross-member cointegration. In this case cointegration between CDS and CB takes place only if the common factors for CDS cointegrate with those of CB spreads. Hence, we test for common factor no-cointegration (case 2 listed above). Gengenbach et al. (2006) propose to test the null of no-cointegration between the factors using the Johansen likelihood ratio test.

Table 2: Gengenbach et al. (2006) cointegration test

\begin{tabular}{lll}
\hline trace test statistic & critical value & cointegration rank \\
\hline $19.16^{* *}$ & 29.68 & 0 \\
8.75 & 15.41 & 1 \\
3.00 & 3.76 & 2 \\
\hline
\end{tabular}

Table 2 presents the results of the Johansen test for cointegration between the estimated common factors identified by Bai and Ng (2004) method. The Johansen trace test, applied to the three estimated common factors, does not find any cointegrating relationship among the unobserved common factors. ${ }^{10}$

\section{Conclusion}

During the 2007-2009 financial crisis, financial markets experienced tremendous perturbation. Credit spreads widened to unprecedented levels and many relations that were considered to be text-book arbitrage before the crisis were severely violated. In particular, the violation of the CDS-bond basis arbitrage has been documented for the US bond market during the financial crisis of 2007-2009 (See Bai and Collin-Dufresne (2014) and Fontana (2009)). In this paper, we stress the same results for the European market by means of a novel econometrics testing procedure robust to the presence of cross section dependence among the individual bonds.

\footnotetext{
${ }^{10}$ To correct for finite sample bias, the trace statistic is multiplied by the scale factor $(T-p L) / T$, where $T$ is the number of the observations, $L$ the lag order of the underlying VAR model and $p$ the number of the variables, see Reimers (1992).
} 


\section{References}

Bai, J. and Collin-Dufresne, P. (2014). The CDS-bond basis. Tech. rep., AFA 2013 San Diego Meetings paper.

— and NG, S. (2002). Determining the number of factors in approximate factor models. Econometrica, 70, 191-221.

— and - (2004). A panic attack on unit root and cointegration. Econometrica, 72, 1127-1177.

Banerjee, A., Marcellino, M. and Osbat, C. (2004). Some cautions on the use of panel methods for integrated series of macroeconomic data. Econometrics Journal, 7, 322-340.

Blanco, R., Brennan, S. and Marsh, I. (2005). An empirical analysis of the dynamic relationship between investment grade bonds and credit default swaps. The Journal of Finance, 60, 2255-2281.

Breitung, J. and Pesaran, M. H. (2008). The Econometrics of Panel Data (Third Edition), chap. Unit roots and cointegration in panels, pp. 279-322.

Campbell, J. and Taksler, G. (2003). Equity volatility and corporate bond yields. The Journal of Finance, 58, 2321-2349.

Castagnetti, C. and Rossi, E. (2013). Euro corporate bond risk factors. Journal of Applied Econometrics, 28, 372-391.

—, - and Trapani, L. (2017). A two-stage estimator for heterogeneous panel models with common factors. Econometrics and Statistics, forthcoming.

FontanA, A. (2009). The persistent negative CDS-bond basis during the 2008/09 financial crisis. Tech. rep., Working paper, Ca'Foscari University of Venice.

Forte, S. and Pena, I. (2009). Credit spreads: An empirical analysis on the informational content of stocks, bond, and cds. Journal of Banking 6 F Finance, 33, 2013-2025.

Gengenbach, C., Palm, F. and Urbain, J. (2006). Cointegration testing in panels with common factors. Oxford Bulletin of Economics and Statistics, 68, 683-719. 
Im, K. S., Pesaran, M. H. and Shin, Y. (2003). Testing for unit roots in heterogenous panels. Journal of Econometrics, 115, 53-74.

LARsson, R. and LyHaGen, J. (2000). Why not use standard panel unit root test for testing PPP. Tech. rep.

Levin, A., Lin, C. F. and Chu, C. S. J. (2002). Unit root tests in panel data: Asymptotic and finite-sample properties. Journal of Econometrics, 108, 1-24.

Longstaff, F., Mithal, S. and Neis, E. (2005). Corporate yield spreads: default risk or liquidity? new evidence from the credit default swap market. The Journal of Finance, 60, $2213-2253$.

NG, S. and Perron, P. (2001). Lag length selection and the construction of unit root tests with good size and power. Econometrica, 69, 1519-1554.

Norden, L. and Weber, M. (2009). The co-movement of credit default swap, bond and stock markets: an empirical analysis. European Financial Management, 15, 529-562.

Reimers, H. E. (1992). Comparison of tests for multivariate cointegration. Statistical Papers, 33, 335-359.

Wagner, M. and Hlouskova, J. (2010). The performance of panel cointegration methods: Results from a large scale simulation study. Econometric Reviews, 29, 182-223.

ZHU, H. (2006). An empirical comparison of credit spreads between the bond market and the credit default swap market. Journal of Financial Services Research, 29, 211-235. 